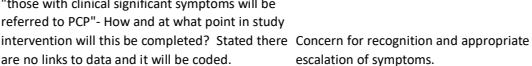

Comments and feedback to applicant regarding Cor
ettical consididerations

\section{Petrinec Amy}

Petrinec Amy
Amy objectives and hypotheses are well matched

Specific hypotheses not stated. The duration of
data collection (60 days) seems short for a 2 year
studellent review of fiterature and use of a
theoretical framework are no links to data and it will be coded. escalation of symptoms.

\section{- unclear what happens if the patient dies in the
ICU -method of randomization not described -} some clinical datat that are collected are not
justified or discussed in the methods section

Mussinin information on tool reliability ynd
validty What does the control group receive for
standard care?
Indicate the rationale for your recommendation
and required changes, if applicable, below. Aditional feedback to applicant

This is a greats study. Picc is becoming widely
recogizized but not so much hor tre family Using
technology for this is a great idea moving forward technology for thisis s a great idea moving forwar
and may lead additional uses of technology for
similar poovulations.

Reasonable budget requests. Question mileage
and parking for investigators.

What a terrifici idea to study an intervention for This is a terrificic proposal, well done. Great area of research,
PIISS-F

the study is already funded- what is the added
tenefiti of the current proposal? How

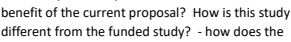

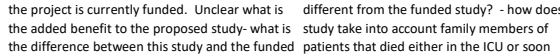

Excellent proposal for a highly relevant study. A few

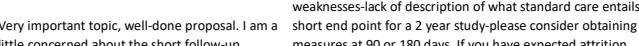

